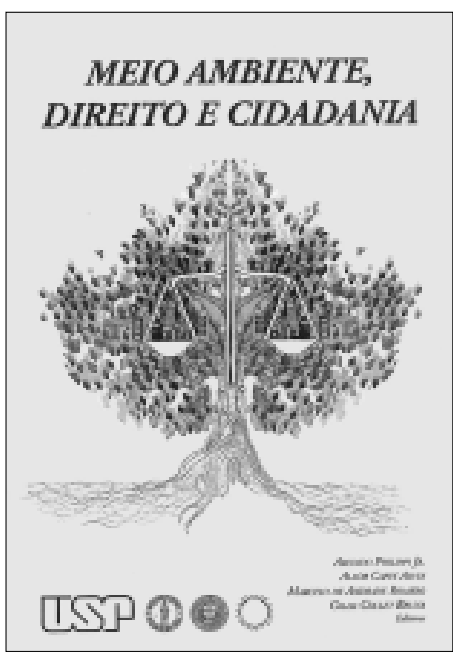

\title{
Meio ambiente, Direito e CIDADANIA
}

PHilipPi Jr, Arlindo; ALVES, Alâor Caffé; roméro, Marcelo de Andrade; Bruna, Gilda Collet (Eds). São Paulo: Núcleo de InFormaÇões em SAÚde Ambiental da Universidade de São Paulo (NisAM-USP), Signus Editora, 2002. $358 \mathrm{P}$

\section{Sheila Walbe Ornstein}

\author{
A questão ambiental e suas diversas faces sob a ótica do direito \\ e da cidadania
}

Esta obra trata de alguns dos principais resultados, pensamentos, reflexões, análises e diretrizes, frutos de anos de esforços liderados pelo Núcleo de Informações em Saúde Pública da Universidade de São Paulo (NISAM), dos aspectos ambientais do meio urbano no contexto contemporâneo (e necessário) da interdisciplinaridade.

O NISAM vem se destacando na Universidade de São Paulo e na esfera nacional como centro de excelência na abordagem do meio ambiente, procurando agregar nesta discussão as instituições de ensino e de pesquisa, as quais devem obrigatoriamente reunir temas integrados sobre meio ambiente e sustentabilidade, enquanto elementos imprescindíveis na formação de especialistas e de pesquisadores em suas respectivas áreas de atuação. São elas, dentro da USP, a Faculdade de Saúde Pública, a Faculdade de Arquitetura e Urbanismo e a de Direito.

Os editores, eles próprios oriundos de formações distintas, Philippi Jr, engenheiro ambiental, Caffé Alves, advogado especialista em direito ambiental, Andrade Roméro, arquiteto especialista em conforto ambiental e em conservação de energia em edificações e Collet Bruna, arquiteta com especialização em urbanismo, revelam de modo expressivo a demanda de profissionais voltados a propostas e soluções para as cidades brasileiras, em seus campos específicos de atuação, a saber, os edifícios, os espaços públicos, a infra e a superestrutura urbanas, os fundamentos socioeconômicos e legais, os deveres e os direitos do consumidor, do morador, ou seja, do cidadão na busca da qualidade de vida.

A obra é densa, dividida em sete partes e em 21 capítulos, nos quais especialistas de elevado nível nas esferas municipal, estadual, nacional e internacional, abordam a temática - meio ambiente - criticamente e, às vezes, de modo complementar e convergente, e outras, de modo divergente, mas todas elas bastante instigantes e reveladoras dos debates atuais por que vêm passando as questões ambientais no país e no mundo (por exemplo, o Estatuto da Cidade, promulgado em 2001 ou ainda os inúmeros acordos de cooperação internacional, 
convenções e tratados assinados por diversos países que pretendem minimizar o efeito estufa, as mudanças climáticas, os desequilíbrios impostos a biodiversidade, as ocupações desenfreadas de encostas e áreas de mananciais, a falta de saneamento básico e uma incontável quantidade de problemas ambientais que afetam drasticamente as cidades latino-americanas de grande porte.

Além da introdução elaborada pelos editores e a conclusão, esta útima de autoria dos docentes da Faculdade de Saúde Pública da USP, Philippi Jr. e Pelicioni, em que é reiterada a necessidade de “.... uso social, justo e ecologicamente equilibrado do território" a partir de ".... uma nova cultura de gestão" ambiental, o livro contempla, em cada bloco temático e em profundidade, aspectos como o meio urbano e a proteção ambiental, a diversidade biológica, engenharia genética e biossegurança, as mudanças climáticas, as unidades de conservação e florestas, a cooperação técnica e financeira, bancos e meio ambiente.

Por ser esta resenhadora arquiteta, mas sem ter a intenção de reduzir a enorme importância dos demais tópicos, chama a atenção, em especial, a parte que aborda o meio ambiente e os aspectos físicos, comportamentais e legais, nos níveis metropolitanos e municipais da questão da proteção ambiental. Nela, saneamento básico (ou a ausência dele), os problemas do efeito estufa, da poluição e os distintos encaminhamentos dados por políticas públicas, por associações e organizações não-governamentais e cooperativas, as tecnologias passíveis de serem adotadas para eventuais ajustes destes problemas e o impacto na qualidade de vida das populações urbanas, principalmente aquelas mais carentes e periféricas, são cuidadosamente tratados.

A compreensão da problemática "mudança climática", sua contribuição para o efeito estufa em nossas regiões metropolitanas também podem auxiliar arquitetos e urbanistas a projetarem edifícios e espaços exteriores que atenuem as conseqüências perversas desse fenômeno, sobretudo, no caso dos projetos e das construções aceleradas das grandes torres, com impactos em seus usuários imediatos e na qualidade de vida da vizinhança urbana em que se localiza em termos das condições de conforto ambiental. Não é à toa que os trabalhos de consultores e de pesquisadores como Daniels (1997) e Yeang (2001), quanto ao conceito de edifício ecológico ou verde, estão sendo debatidos intensamente no meio acadêmico (GONÇALVES, 2001), embora as recomendações geradas nesse meio científico e já implementadas em países desenvolvidos, infelizmente, estejam longe de influenciar, de modo prático, os agentes efetivos do mercado imobiliário.

A edição é bem cuidada, permitindo uma leitura didática e acessível por bloco temático, segundo uma estrutura lógica de assuntos.

Enfim, a obra, além de colocar à disposição do público mais amplo graduandos, pós-graduandos, consultores e profissionais - reflexões críticas sobre o meio ambiente e sua visão interdisciplinar que vem ocorrendo há anos no NISAM, em atividades de ensino e de pesquisa, cumprindo, assim, uma das tarefas importantes da USP, que é a da divulgação abrangente de iniciativas como esta, de perfil de prestação de serviços à comunidade, trata-se de obra imprescindível para consulta por aqueles que se interessam, de modo consciente, pelos desígnios de nossas cidades, os quais se tem a esperança que já não sejam tão poucos e que estejam em número crescente. 


\section{Referências}

DANIELS, Klaus. The technology of ecology building: Basic principles and measures, examples and ideas. Berlim: Birkhäuser, 1997. 301 p.

GONÇALVES, Joana Carla Soares. A cidade de São Paulo e o processo de verticalização nos anos 90 com referência a três estudos de caso. In: Cadernos Técnicos do AUT. São Paulo: Faculdade de Arquitetura e Urbanismo da Universidade de São Paulo, n. 8, p. 15-60, 2001.

YEANG, Ken. El rascacielos ecológico. Barcelona: Editorial Gustavo Gili, AS, 2001. 303 p.

\section{Sheila Walbe Ornstein}

Doutora, professora titular da Faculdade de Arquitetura e Urbanismo, pesquisadora sênior em avaliação pós-ocupação do ambiente construído do Núcleo de Pesquisa em Tecnologia da Arquitetura e Urbanismo da Universidade de São Paulo e bolsista do Conselho Nacional de Desenvolvimento Científico e Tecnológico (CNPq) e orientadora no curso de Pós-Graduação FAUUSP. 